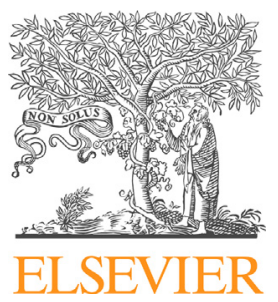

${ }^{\mathrm{a} D e p a r t m e n t}$ of Paediatric Urology, Royal Manchester Children's Hospital,

Manchester, UK

bBrady Urological Institute, Johns Hopkins Hospital, Baltimore, USA

'Department of Paediatric Urology, UZ Leuven, Leuven, Belgium

${ }^{\mathrm{d}}$ Department of Paediatric Urology, University Children's Hospital, Zurich, Switzerland

${ }^{\text {e}}$ Department of Paediatric Nephro/Urology, Ospedale Bambino Gesu, Rome, Italy

Correspondence to:

R.M. Cervellione, Royal

Manchester Children's Hospital, Oxford Road, Manchester M13 9WL, UK

raimondo.cervellione@cmft.nhs.uk

(R.M. Cervellione) mantovalbe@gmail.com

(A. Mantovani)

jgearha2@jhmi.edu

(J. Gearhart)

guy.bogaert@uzleuven.be

(G. Bogaert)

rita.gobet@kispi.uzh.ch

(R. Gobet)

paolo.caione@opbg.net

(P. Caione)

alan.dickson@cmft.nhs.uk

(A.P. Dickson)

\section{Keywords}

Bladder exstrophy; Cloacal

exstrophy; Epispadias; Epide-

miology; Demography

Received 2 July 2014

Accepted 24 March 2015

Available online $x x x$

\title{
Prospective study on the incidence of bladder/cloacal exstrophy and epispadias in Europe
}

\author{
Raimondo M. Cervellione ${ }^{a}$, Alberto Mantovani ${ }^{a}$, John Gearhart ${ }^{\mathrm{b}}$, \\ Guy Bogaert ${ }^{\mathrm{C}}$, Rita Gobet ${ }^{\mathrm{d}}$, Paolo Caione ${ }^{\mathrm{e}}$, Alan P. Dickson ${ }^{\mathrm{a}}$
}

Summary

\section{Objective}

On behalf of the European Society of Paediatric Urology (ESPU), a prospective study was designed with the aim of defining the actual number of babies born with bladder exstrophy, cloacal exstrophy, and epispadias in Europe over a 12-month period, and verifying the distribution of the exstrophy patients born during the study period among the different paediatric urology centres in Europe.

\section{Study design}

The study was structured with a chief investigator and one national investigator for each country enrolled in the study. The national investigators nominated one local investigator for each European centre of paediatric surgery/paediatric urology and urology where the exstrophy complex could potentially be treated. The local investigators were responsible for reporting babies treated in their institutions for bladder/cloacal exstrophy and/or epispadias. During 2010, every 3 months, an electronic survey (Figure) was e-mailed to the local investigators asking them to report babies treated or referred for treatment during the previous 3 months.

\section{Results}

One-hundred and sixteen centres in 27 European counties were enrolled in the study. The overall response rate for the four online surveys was $79 \%$. Two-hundred and thirty-eight babies were reported to be born with a condition within the bladder exstrophy epispadias complex (BEEC): 71 primary epispadias (66 males), 146 classic bladder exstrophy ( 97 males) of which two were female bladder exstrophy variant, and 21 cloacal exstrophy (17 males). Two of 67 (3\%) male epispadias, 24/146 (16.4\%) bladder exstrophy, and 6/21 (28\%) cloacal exstrophy were antenatally diagnosed. Associated anomalies were reported in 2/71 (2.8\%) epispadias patients, 8/146 (5.5\%) bladder exstrophy patients, and 15/21 (71.4\%) cloacal exstrophy patients. One-hundred and fortyseven $(62 \%)$ of the 238 babies born in Europe with a condition within the exstrophy spectrum during 2010 were transferred from other institutions for treatment ( 36 male epispadias, 97 bladder exstrophy, and 14 cloacal exstrophy). Only 12 centres treated six or more exstrophy and or epispadias patients during the study period; 52 treated between one and five patients, of which 22 treated only one case in 12 months.

\section{Discussion}

This study provides a contemporary incidence of the BEEC in Europe. It demonstrates also that only a minority (19\%) of the European centres involved in the treatment of exstrophy can be considered "high volume" exstrophy centres.

\section{Conclusion}

There is a case for proposing a rationalisation of the treatment of this group of conditions in a small number of exstrophy units around Europe.
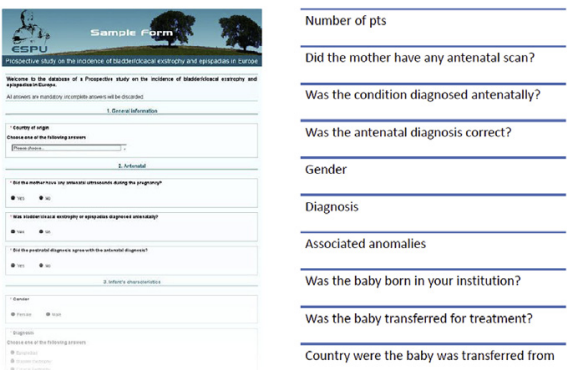

Figure Sample of the online questionnaire emailed to the local investigators. 


\section{Introduction}

According to Eurostat, 5421000 live births were registered in the EU27 in 2008 [1]. Considering the published incidence of the bladder exstrophy complex (male epispadias 1:117 000 [2]; female epispadias 1:484 000 [2]; classic bladder exstrophy 1:37 000 [3]; cloacal exstrophy 1:200 000 [4]) in the EU27 every year, about 146 classic bladder exstrophy, 46 male epispadias, 27 cloacal exstrophy, and 11 female epispadias patients would have been expected to be born. Routine antenatal screening ultrasound is commonly used in most European countries. The EUROSCAN study [3] was conducted in 12 European countries between 1996 and 1998 monitoring over 709000 births. Fifty-two per cent of the bladder exstrophy cases were antenatally detected. The study showed that $80 \%$ of the antenatally detected cases of bladder exstrophy were terminated, the incidence of bladder exstrophy in Europe was 1:37 000 foetuses, but only one baby every 71000 was actually born. What is the incidence of the exstrophy complex in Europe at the moment? Also, what is the average exposure of European paediatric urologists to exstrophy? Is there a need for promoting centralisation of treatment of exstrophy throughout Europe, as has already been adopted in the UK and the Netherlands?

To address these questions, the authors have organised, on behalf of the European Society of Paediatric Urology (ESPU), a prospective study, the aim of which was to define the actual number of babies born with bladder exstrophy, cloacal exstrophy, and epispadias in Europe over a 12month period and to verify the distribution of the exstrophy patients born during the study period among the different paediatric urology centres in Europe. The study did not investigate the rate of termination of pregnancy when antenatal diagnosis was made.

\section{Methods}

The study was announced at the European Society of Paediatric Urology (ESPU) annual meeting in 2007 [5].

It was structured with a chief investigator (RMC), one national investigator for each country enrolled in the study, and a local investigator for each centre enrolled in the study.

The national investigators were selected using primarily the ESPU members' database. For countries where more than one ESPU member was available, the national investigator was chosen based on perceived academic proficiency. For countries where no ESPU member was available, the European Paediatric Surgeons' Association (EUPSA) and the World Federation of Associations of Paediatric Surgeons (WOFAPS) databases were consulted. If necessary, further research was conducted looking at the corresponding author of recent paediatric urology publications. The potential national investigators were contacted by e-mail and invited to be enrolled into the study during 2009.

The national investigators were responsible for providing a list of centres of paediatric surgery, paediatric urology, and urology where the exstrophy complex could potentially be treated in their countries during 2010. The national investigators nominated a local investigator for each centre that they identified and provided an e-mail address for each local investigator.

The study website www.espu.org/be_study was published on the ESPU homepage with information regarding the study and contact details. Any paediatric urologist, paediatric surgeon, or urologist whose centre had not been listed by the national investigators was invited to contact the chief investigator directly with the opportunity of being added as local investigator for her/his institution.

The local investigators were responsible for reporting babies treated in their institutions for bladder/cloacal exstrophy and/or epispadias during the study period.

All the potential local investigators nominated by the national investigators and those who self-nominated, were e-mailed before the beginning of the study to confirm their availability to be involved. Only those who confirmed their interest were enrolled in the study.

During the 12-month study period, from January to December 2010, every 3 months, an e-mail was sent through the ESPU server inviting the local investigators to report new babies treated or transferred for treatment at their institution or to state that no new cases had been diagnosed at their institution during the previous 3-month period. The local investigators were also asked to state if patients were transferred to them for treatment from other institutions nationally or internationally.

The e-mail was linked to the reporting page of the study website www.espu.org/be_study. The local investigators had to enter the username and to fill the electronic form which asked the following questions: 1-Number of patients, 2-Did the mother have any antenatal scan?, 3-Was the condition diagnosed antenatally?, 4-Was the antenatal diagnosis correct?, 5-Gender, 6-Diagnosis, 7-Associated anomalies, 8-Was the baby born in your institution?, 9Was the baby transferred for treatment?, and 10-Country from which the baby was transferred.

Feedback about the study compliance was published after every survey on the study website (http: / /www.espu. org/be_study/index.php?id =58).

Following the fourth study survey, an excel database was provided by the ESPU webmaster based on the results of the four surveys.

In 2011 Eurostat published the demographic data for the European countries and surrounding areas [6]. Demographic data for Kosovo were published by the Ministry of Public Administration of Kosovo [7]. Demographic data for Bosnia and Herzegovina was published by the Federal Office of Statistics of Bosnia and Herzegovina [8]. The Eurostat, Kosovo, and Bosnia and Herzegovina data were used to obtain the number of babies born during 2010 in the 27 European countries involved in the study. The incidence of epispadias, the incidence of bladder exstrophy, and the incidence of cloacal exstrophy in the different countries were calculated as follows: number of live births/number of epispadias; number of live births/bladder exstrophy (including variants); and number of live births/cloacal exstrophy (including variants) in each of the 27 countries involved in the study. The number of babies treated for a condition within the bladder exstrophy spectrum in each centre enrolled in the study was also calculated. In 2011 the initial results of the study were presented at the ESPU annual meeting [9]. Subsequently, an e-mail was sent to the 
Table 1 Associated anomalies.

\begin{tabular}{|c|c|c|c|c|c|c|c|c|c|c|}
\hline Condition & Total number & Multiple & Cardiac & ARM & Orthopaedic & CNS & Trisomy 21 & Genetic & Urinary & Tot $\%$ \\
\hline Epispadias & 71 & & & & & & & 1 & 1 & 2.8 \\
\hline Bladder exstrophy & 146 & 3 & 1 & 2 & & & 1 & & 1 & 5.5 \\
\hline Cloacal exstrophy & 21 & 5 & 2 & & 2 & 5 & 1 & & & 71.4 \\
\hline
\end{tabular}

local investigators who had reported during the study period babies treated at their institution for a condition within the exstrophy spectrum, asking for confirmation of the data provided. If no answer was received within a month, the data were considered accurate.

\section{Results}

Twenty-nine countries were invited to take part in the study. No national investigators accepted this role for Ireland and Norway; therefore these two countries were excluded from the study. Twenty-seven national investigators were enrolled in the study in 27 countries in Europe and surrounding areas; the list of the national investigators can be found at http://www.espu.org/be_ study/index.php?id $=44$. One-hundred and seventy local investigators were identified and 116 agreed to take part in the study. The full list of the centres enrolled in the study divided by country can be found at http://www.espu.org/ be_study/index.php?id $=44$.

For the first survey, 105/116 (91\%) local investigators responded when asked to report babies born with a condition within the exstrophy spectrum between January and March 2010; 88/116 (76\%) responded to the second survey to report babies born between April and June 2010; 79/116 (68\%) responded to the third survey to report babies born between July and September 2010; 87/ 116 (75\%) responded to the fourth and last survey to report babies born between October and December 2010. The overall response rate for the four online surveys was $79 \%$.

During the 12-month study period, 238 babies were reported born with a condition within the exstrophy complex during the study period: 71 primary epispadias (67 males), 146 bladder exstrophy ( 97 males) of which two were female bladder exstrophy variant, and 21 cloacal exstrophy (17 males).

Diagnosis was made antenatally for 2/67 (3\%) male epispadias, 24/146 (16.4\%) bladder exstrophy, and 6/21 (28\%) cloacal exstrophy.

Associated anomalies (Table 1 ) were reported in 2/71 (2.8\%) epispadias patients, 8/146 (5.5\%) bladder exstrophy patients, and 15/21 (71.4\%) cloacal exstrophy patients.

In the 27 countries involved with the study during 2010, 6651000 babies were born [6-8]. Fig. 1 provides the distribution of the bladder exstrophy complex in the 27 countries enrolled in the study. Table 2 reports the number of live births and the number of babies born with epispadias, bladder exstrophy, and cloacal exstrophy in the 22 countries enrolled in the study. Table 3 provides the overall incidence of epispadias, bladder exstrophy, and cloacal exstrophy in Europe.
One-hundred and forty-seven (62\%) of the 238 babies born in Europe with a condition within the exstrophy spectrum during 2010 were transferred from other institutions for treatment (36 male epispadias, 97 bladder exstrophy, and 14 cloacal exstrophy). One-hundred and thirty-six patients were transferred to a centre within the native country and five were transferred to other European countries (one to France and four to Germany). Another 13 patients (two male epispadias, two female epispadias, eight bladder exstrophy, and one cloacal exstrophy) were transferred to Europe from countries outside Europe; these 13 babies were not considered to calculate the incidence of the exstrophy complex in Europe but were included in the figures about the number of babies treated in the different centres in Europe.

\section{Discussion}

This study confirms the data from Goyal et al. [10] who found an antenatal diagnosis rate of $25 \%$ in the BE and CE conditions. Termination of pregnancy is still often advised when BE is detected antenatally [3]; however, because exstrophy can be detected antenatally in only a minority of the cases, the incidence of BE in Europe is similar to the data previously published [2].

Rickham reported an incidence of bladder exstrophy in the Liverpool region (UK) of $1 / 40000$ between 1942 and 1953, and $1 / 10000$ between 1953 and 1959. The incidence

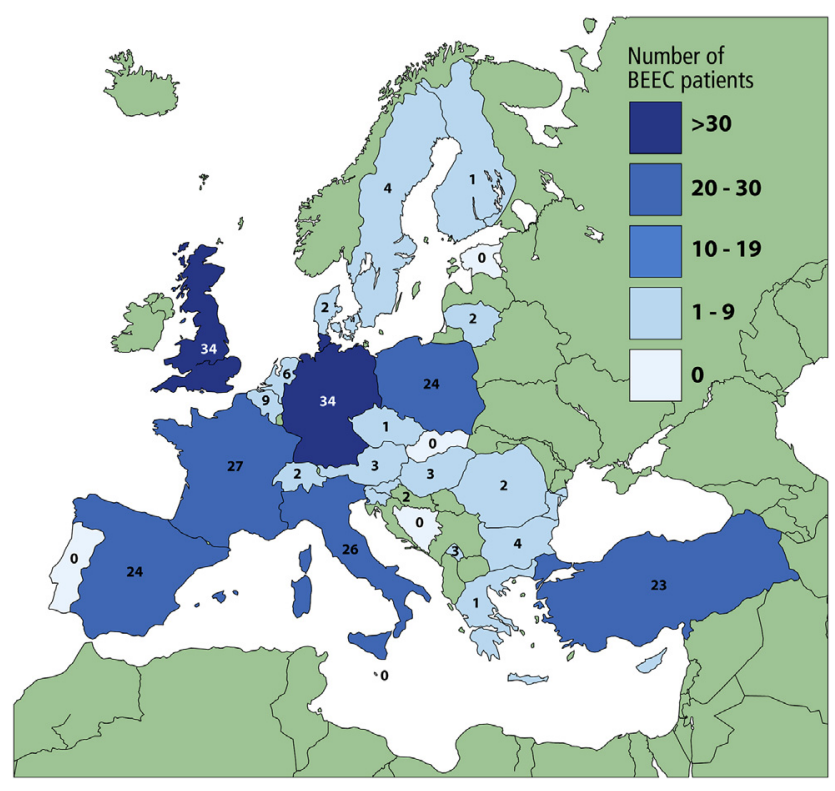

Figure 1 Number of BEEC newborns in 2010 in the 27 countries enrolled in the study. 
Table 2 Number of live births, number of babies born with epispadias, bladder exstrophy, and cloacal exstrophy in the 22 countries enrolled in the study and incidence of the conditions in the 22 countries.

\begin{tabular}{|c|c|c|c|c|c|}
\hline Country & Live births & Female epispadias & Male epispadias & Bladder exstrophy & Cloacal exstrophy \\
\hline Austria & 78700 & 0 & $2(1: 39300)$ & $1(1: 78700)$ & 0 \\
\hline Belgium & 127000 & 0 & $2(1: 63500)$ & $5(1: 25400)$ & $2(1: 63500)$ \\
\hline Bosnia \& Herzegovina & 9000 & 0 & 0 & 0 & 0 \\
\hline Bulgaria & 75500 & $1(1: 75$ 500) & $1(1: 75500)$ & $2(1: 37700)$ & 0 \\
\hline Czech Republic & 117200 & 0 & 0 & $1(1: 117$ 200) & 0 \\
\hline Denmark & 63400 & 0 & 0 & $2(1$ in 31700$)$ & 0 \\
\hline Estonia & 15800 & 0 & 0 & 0 & 0 \\
\hline Finland & 61000 & 0 & 0 & $1(1: 61000)$ & 0 \\
\hline France & 829000 & 0 & $10(1: 82$ 900) & $17(1: 48700)$ & 0 \\
\hline Germany & 677900 & $1(1: 677900)$ & $7(1: 96800)$ & $21(1: 32$ 200) & $5(1: 135500)$ \\
\hline Greece & 115500 & 0 & 0 & $1(1: 135500)$ & 0 \\
\hline Hungary & 90400 & $1(1: 90400)$ & 0 & $2(1: 45$ 200) & 0 \\
\hline Italy & 561900 & $2(1: 280900)$ & $10(1: 56100)$ & $13(1: 43200)$ & $1(1: 561900)$ \\
\hline Kosovo & 33700 & 0 & 0 & $3(1: 11200)$ & 0 \\
\hline Lithuania & 35600 & 0 & 0 & $1(1: 35600)$ & $1(1: 35600)$ \\
\hline Malta & 4000 & 0 & 0 & 0 & 0 \\
\hline Netherlands & 183900 & 0 & $4(1: 45900)$ & $2(1: 91900)$ & 0 \\
\hline Poland & 413300 & 0 & $9(1: 45800)$ & $10(1: 41300)$ & $5(1: 82600)$ \\
\hline Portugal & 101300 & 0 & 0 & 0 & 0 \\
\hline Romania & 212200 & 0 & 0 & 0 & $2(1: 106$ 100) \\
\hline Slovakia & 60400 & 0 & 0 & 0 & 0 \\
\hline Slovenia & 21700 & 0 & 0 & $2(1: 10800)$ & 0 \\
\hline Spain & 480000 & 0 & $11(1: 43600)$ & $12(1: 40000)$ & $1(1: 480000)$ \\
\hline Sweden & 115600 & 0 & 0 & $4(28900)$ & 0 \\
\hline Switzerland & 80000 & 0 & 0 & $3(1: 26700)$ & 0 \\
\hline Turkey & 1279000 & 0 & $4(1: 319700)$ & $17(1: 75200)$ & $2(1: 639500)$ \\
\hline UK & 807300 & 0 & $6(1: 134500)$ & $26(1: 31000)$ & $2(1: 403600)$ \\
\hline Total & 6650300 & $5(1: 1300000)$ & $66(1: 100700)$ & $146(1: 45500)$ & $21(1: 316700)$ \\
\hline
\end{tabular}

was calculated retrospectively based on the number of new cases seen in Liverpool and no data are available about the referral territory during the study period [11].

In 1984, Shapiro and colleagues studied the epidemiology of the exstrophy complex sending questionnaires to 92 paediatric urologists in North and South America and Europe asking about recurrence of exstrophy in siblings, occurrence of exstrophy in multiple births, and recurrence of the exstrophy-epispadias complex in offspring of patients with these anomalies. The recurrence of exstrophy was identified in only nine of the 2500 families survived (1/ 275). They reported 17 twins with at least one of the twins

Table 3 Incidence of male epispadias, female epispadias, bladder exstrophy, cloacal exstrophy, and the bladder exstrophy complex in general.

\begin{tabular}{ll}
\hline Condition & Incidence $^{a}$ \\
\hline Male epispadias & $1 / 101000$ \\
Female epispadias & $1 / 1300000$ \\
Bladder exstrophy & $1 / 46000$ \\
Cloaca exstrophy & $1 / 317000$ \\
Bladder exstrophy complex & $1 / 30000$ \\
\hline
\end{tabular}

Incidence calculated among the 27 European countries enrolled in the study.

${ }^{\text {a }}$ Data approximated to 1000 . affected by exstrophy (including the literature review). They also reported a recurrence risk of the exstrophy and epispadias complex in 215 offspring being approximately one in 70 live births [12].

The international clearinghouse for "birth defects monitor systems" published data in 1987 about the incidence of bladder/cloacal exstrophy and epispadias based on nearly 6.3 million births (24 different monitoring programs around the world). Three-hundred and fifty-six infants were identified with bladder exstrophy or primary epispadias with an overall incidence of 3.3 per 100000 births (range 2.1-4.7). The incidence of cloacal exstrophy was estimated as 1/200 000 [4].

In 1986, Ziegler and colleagues estimated an incidence of cloacal exstrophy as one in 400000 . However, this figure, which has been constantly cited in the exstrophy literature in the last 28 years, is not based on a study but on the assumption that: 'Of vesical exstrophy complex of anomalies, 60\% are classical exstrophy; 30\% are epispadias (including balantic, penile, subsymphysial, and penopubic); and $10 \%$ comprise the cloacal exstrophies, superior vesical fissure, duplicate exstrophy or pseudoexstrophy. Since the incidence of classic bladder exstrophy is 1 in 10000 births, cloacal exstrophy and its variants would be expected in about 1 in 400 000' [13]. Based on the more accurate literature now available, this citation should be considered out of date. 
In 1994, Yang and colleagues reported 22 cases of bladder exstrophy between 1980 and 1987 in Maryland, Washington D.C. and six North Virginia counties with a birth prevalence 0.40 per 10000 live births (confidence interval 0.26-0.61) [14].

Martinez-Frias and colleagues in 2001 reported the incidence of bladder exstrophy and cloacal exstrophy among a population of 1601860 consecutive live born infants between 1976 and 1996 in Spain. Eight children were born with cloacal exstrophy and 45 with bladder exstrophy with a prevalence of 0.005 and 0.28 per 10000 live births, respectively [15].

Nelson and colleagues collected data on the epidemiology of bladder exstrophy in the USA between 1988 and 2000. Two-hundred and five newborns with exstrophy were identified over a 9452110 sample. The national incidence was calculated to be 2.15 per 100000 [16].

Caton and colleagues reported in 2007 a prevalence of bladder exstrophy in the New York State of 2.7 per 100000 live births over a 17-year study period between 1983 and 1999 [17].

This manuscript represents the first prospective study focused on the incidence of the exstrophy complex. The authors report that 238 patients were born in Europe with exstrophy or epispadias during a 12-month period. The authors recognise that babies treated in centres which did not take part in the study have not been identified. The creation of the prospective registry for this study represented a demanding task that took place between September and December 2009. The authors believe that, based on the study design, the risk of having missed European centres which are actively involved in the treatment of exstrophy is minimal. The national investigators created a list of all the units in their countries that could treat exstrophy in 2010. Only cases treated or transferred for treatment during the study period were reported by the local investigators. In the authors' view, this study created a more accurate exstrophy registry than the previous studies on this subject. The authors did not involve any foetal medicine unit; therefore no data on termination of pregnancy are available with this study. The EUROSCAN study [3] had already provided accurate data on termination of pregnancy when exstrophy is identified antenatally.

The incidence of female epispadias is most likely underestimated by this study because the condition is rarely diagnosed at birth.

The complexity of this group of conditions requires a multidisciplinary approach to address the urological, orthopaedic, gastrointestinal, gynaecological, and psychological issues associated with exstrophy. The rarity of exstrophy does not facilitate the development of multidisciplinary teams with good expertise in the understanding and management of this condition, and very often exstrophy is managed by a surgeon with only occasional exposure to exstrophy.

Only 12 centres in Europe were able to treat six or more exstrophy and or epispadias during the study period. On the other hand, 52 centres treated between one and five patients during 2010, of which 22 treated only one case in 12 months.

There is a case for centralising the treatment of exstrophy and epispadias in a smaller number of units around
Europe to ensure optimal quality of care for patients with exstrophy and their families. The UK and the Netherlands represent at the moment the only models of centralisation of treatment of exstrophy in Europe. Both the Manchester and the London exstrophy units treated more than six exstrophy patients during the study period [18]. If the treatment of bladder exstrophy in Europe could be limited to a small number of centres, each would manage a significant number of exstrophy patients every year which would allow the development of good clinical expertise within a relatively short period of time. This would also allow the development of prospective studies at a level much superior to what can be achieved in the current situation.

\section{Conclusion}

This first prospective epidemiological study focused on the bladder exstrophy complex in Europe provides a contemporary incidence of the BEEC. The study demonstrated also that only a minority of the European Paediatric Urology Centres can be considered "high volume" exstrophy units. Considering the need for an experienced multidisciplinary team for the optimal treatment of exstrophy, there is a strong case for proposing a rationalisation of the treatment of this group of conditions in a small number of units around Europe to ensure optimal quality of care.

\section{Conflict of interest}

None.

\section{Funding}

None.

\section{Acknowledgments}

The Authors would like to express their gratitude to $\mathrm{Mr}$ Clément Ekstein, ESPU webmaster, for his IT support before, during, and after the study period; Mr Manfred te Grotenhuis, Department of Sociology, Radboud University Nijmegen, the Netherlands, for the statistical advise; Prof Sedar Tekgül for supporting the study; all the National and Local investigators for their precious contribution.

\section{References}

[1] Eurostat. http://epp.eurostat.ec.europa.eu/cache/ITY PUBLIC/3-03082009-AP/EN/3-03082009-AP-EN.PDF [accessed 24.09.14].

[2] Gearhart JP, Jeffs RD. Exstrophy of the bladder, epispadias, and other bladder anomalies. In: Walsh PC, Retik $A B$, Stamey TA, Vaughan Jr ED, editors. Campbell's urology. 6th ed., vol. 2. Phyladelphia: W.B. Saunders Co; 1992. p. 1172-815 [chapter 46].

[3] Wiesel A, Queisser-Luft A, Clementi M, Bianca S, Stoll C, the EUROSCAN Study Group. Prenatal Detection of congenital Renal Malformation by Fetal Ultrasonographic Examination: an 
analysis of 709,030 births in 12 European countries. Eur J Med Genet 2005;48:131-44.

[4] International Clearinghouse for Birth Defects Monitoring Systems. Epidemiology of bladder exstrophy and epispadias: a communication from the international clearinghouse for birth defects monitoring systems. Teratology 1987;36:221-7.

[5] ESPU. http://www.espu.org/members/previous-eventsabstracts/67-2007-meeting-brugge-belgium/100-2007programme-and-abstracts [accessed 24.09.14].

[6] Eurostat. http://epp.eurostat.ec.europa.eu/cache/ITY PUBLIC/3-01042011-BP/EN/3-01042011-BP-EN.PDF [accessed 24.09.14].

[7] www.ks-gov.net/esk [accessed 24.09.14].

[8] Statistièki Godišnjak/Ljetopis Federacije Bosne I Hercegovine. Statistical Yearbook 2011. http://www.fzs.ba/ Godisnjak2011k.pdf [accessed 24.09.14].

[9] ESPU. http://www.espu.org/members/previous-eventsabstracts/75-2011-meeting-copenhagen-denmark/130-2011programme-and-abstracts [accessed 24.09.14].

[10] Goyal A, Fishwick J, Hurrell R, Cervellione RM, Dickson AP. Antenatal diagnosis of bladder/cloacal exstrophy: challenges and possible solutions. J Pediatr Urol 2012;8(2):140-4.

[11] Rickham PP. The incidence and treatment of Ectopia Vescicae. Proceeding R Soc Med 1961;389.
[12] Shapiro E, Lepor H, Jeffs R. The inheritance of the exstrophyepispadias complex. J Urol 1984;132(2):308-10.

[13] Ziegler MM, Duckett JW, Howell CG. Cloacal exstrophy. In: Welch KJ, Randolph JG, Ravitch MM, O’Neil JA, Rowe MI, editors. Pediatric surgery. Chicago: Year Book Medical Publishers; 1986. p. 764-71 [chapter 76].

[14] Yang P, Khoury MJ, Stewart WF, Beaty T, Beaty TH, Chee E, et al. Comparative epidemiology of selected midline congenital abnormalities. Genet Epidemiol 1994;11:141-54.

[15] Martinez-Frias ML, Bermejo E, Rodriguez-Pinilla E, Frias JL. Exstrophy of the cloaca and exstrophy of the bladder: two different expressions of a primary developmental field defect. Am J Med Genet 2001;99:261-9.

[16] Nelson C, Dunn RL, Wei JT. Contemporary epidemiology of bladder exstrophy in the united states. J Urol 2005;173(5): $1728-31$.

[17] Caton AR, Bloom A, Druschel CM, Kirby R. Epidemiology of the bladder and cloacal exstrophies in New York State, 1983-1999. Birth Defects Res A Clin Mol Teratol 2007;79:781-7.

[18] NHS England. 2013/14 NHS standard contract bladder exstrophy service (children). http://www.england.nhs.uk/wpcontent/uploads/2013/06/e02-blad-exs-serv-child.pdf [accessed 24.09.14]. 